\title{
A autorreferencialidade na TV brasileira: estratégias e formatos
}

\author{
Maria Lília Dias de CASTRo
}

UFSM - Brasil - mlilia@terra.com.br Graduação em Letras pela Universidade Federal do Rio Grande do Sul e pós-doutorado em Comunicação pela Universidade de Paris III, Sorbonne Nouvelle. Atua especificamente com temas voltados para os campos da publicidade e da televisão. Faz parte do PPGCOM da Universidade Federal de Santa Maria.

\begin{abstract}
Resumo
O presente artigo centra-se na discussão do fenômeno da promoção, no âmbito da televisão comercial brasileira, e procura formular uma espécie de gramática do promocional, examinando as regras em que se funda e as estratégias que estruturam as produções televisuais. Como objeto empírico, elege algumas chamadas de caráter promocional, exibidas nos intervalos comerciais e veiculadas pela Rede Globo de Televisão, nos últimos cinco anos. A intenção dessas peças é chamar a atenção do telespectador para a grade de programação, para a emissora, que assim aproveita a ocasião para falar de si mesma.
\end{abstract}

\section{Palavras-chave}

TV brasileira, formatos, estratégias, telejornalismo, TV comercial.

\begin{abstract}
This paper focuses on the phenomenon of promoting discussion within the Brazilian commercial television, and seeks to formulate a kind of grammar of the promotional, examining the rules which underpin and the strategies that structure televisual productions. As empirical object, elects some calls of promotional character, aired in commercials breaks and broadcasted by Globo TV in the last five years. The intention of these pieces is to call the attention of the viewer to the program schedule, to the channel, that takes the opportunity to talk about itself.
\end{abstract}

\section{Keywords}

Brazilian TV, formats, strategies, telejournalism, commercial TV.

Artigo recebido em 21/08/2012

Aprovado em 21/03/2013 
o momento em que se examina a televisão comercial no Brasil, na perspectiva do duplo papel que ela assume como veículo de comunicação e como empresa voltada à defesa do seu negócio, impõe-se um novo olhar sobre suas funções. Assim, ao lado dos tradicionais pilares - informação, educação e entretenimento -, não se pode negar que existe uma outra que, inclusive, sobredetermina as demais: a promoção. Seu reconhecimento acarreta uma perspectiva diferenciada no exame dessa mídia, que implica o entendimento de um princípio desencadeador que subsume todos os discursos em televisão. Nada é feito gratuitamente, e tudo se volta para o benefício da emissora de televisão e para a empresa de comunicação.

Essa constatação levou à formulação de uma verdadeira gramática do promocional, o que significa uma instância maior, regida por determinadas lógicas que, depois, atualizam-se estrategicamente para receber configurações específicas. Isso representa a construção de um percurso de investigação que vai do geral ao particular e, em se tratando de produção textual, de um patamar abstrato, relativo à definição das estratégias empregadas, até a concretude das manifestações, contidas no texto.

Dentro das configurações possíveis, elege-se um tipo de formato: a chamada autorreferencial da Rede Globo de Televisão ${ }^{1}$, para mostrar, no âmbito da discursivização, as estratégias privilegiadas e as soluções encontradas. Além disso, o trabalho privilegia chamadas veiculadas ao longo dos últimos cinco anos, examinando e comparando as alterações que foram tomando lugar nessa fala reiterada da emissora.

A perspectiva teórica adotada, dentro da vertente semiótica de origem francesa, é compatível com a análise da produção de sentido do discurso promocional televisivo, o que implica necessariamente um olhar atento às especificidades de sua construção e às inter-relações que nele se estabelecem. A essa linha de investigação, agregam-se autores mais contemporâneos, com interesses voltados especificamente ao televisual, tais como François Jost, Paolo Fabbri, Jacques Fontanille, Eliseo Verón e Patrick Charaudeau,

1 Rede Globo de Televisão é a empresa de comunicação com maior índice de audiência no país (só para exemplificar, na semana de 09 a 15/01/12, a telenovela em exibição - Fina Estampa - alcançou 47\% de audiência e $78 \%$ de share; enquanto o Jornal Nacional obteve $35 \%$ de audiência e $63 \%$ de share). 
Estudos em Jornalismo e Mídia - Vol. $10 \mathrm{~N}^{\circ} 2$ - Julho a Dezembro de 2013

cujas perspectivas teóricas auxiliaram na articulação dos rumos aqui propostos.

\section{Percurso de investigação}

A reflexão em torno do promocional é o resultado de uma trajetória investigativa iniciada com o estudo de peças publicitárias exibidas em intervalos da programação televisual. Restrita, naquela ocasião, à publicidade stricto sensu, o objetivo foi estudar a produção de sentido dessas peças, analisando lógicas e estratégias comunicativas e discursivas, presentes em suas manifestações.

Em um momento seguinte, e alargando o âmbito da pesquisa, a centralidade passou a ser menos a publicidade circunscrita à peça e mais as ações publicitárias realizadas na e pela televisão como um todo, naquilo que se denominou de publicidade lato sensu. Esse posicionamento levou em conta a televisão a partir do duplo papel que ela ocupa no mundo globalizado: tanto se apresenta como veículo de comunicação, de seus produtos e daqueles propostos por anunciantes externos; como é reconhecida como empresa que depende de um bom desempenho para garantir posição no mercado. Essa condição obriga a televisão a recorrer à dinâmica publicitária para estabelecer proximidade com o público, sobretudo porque, como empresa, ela necessita dar sustentabilidade ao seu negócio, garantindo o aumento da audiência e a obtenção de margens comerciais que possibilitem os investimentos para atualização tecnológica, pagamento de custos fixos e variáveis de obtenção de lucros.

A duplicidade de papeis permitiu, na continuidade do percurso, a reflexão em torno de uma noção que se considera fundante na televisão comercial brasileira: a promocionalidade, que lida indistintamente com a comercialização de espaços para os anunciantes externos e com a abertura de espaços para a fala sobre a própria produção. Assim se cunhou o termo promocional, ao reconhecer que, a par das funções de informação, educação e entretenimento, e talvez despercebida da maioria do público, a promocionalidade constitui uma outra função, talvez a principal, que permeia as demais, e que fica quase sempre sutilmente esquecida. 
Assim compreendido, o conceito de promoção comporta uma dupla direção aparentemente indissociável: (1) a publicização e (2) a projeção. A publicização diz respeito à ação de divulgar, de propagar, de dar a conhecer, a um público determinado, aspectos positivos e/ou vantagens de qualquer produto, marca, valor ou serviço, através de recursos de ordens diferentes que possam estabelecer vínculo com esse público. A finalidade desse verdadeiro jogo de convencimento é levar o consumidor à aquisição do produto, à aceitação da marca e/ou à aprovação do serviço, para o estabelecimento de relações de troca.

Nessa medida, a publicização funciona como mediação entre o interesse de um enunciador (anunciante) e o fortalecimento do consumo, vale dizer, entre a ordem econômica e os valores sociais e culturais que ela, de certa forma, mobiliza.

Já a projeção diz respeito à ação de lançar para frente, de tornar alguém ou algo conhecido e respeitado por suas atividades, de conferir respeito, credibilidade ao produto, pessoa, marca ou serviço. Combinando os valores da sociedade com a natureza e os interesses do público, esse tipo de promoção converte-se em movimento de exaltação, de influência, de poder a tudo que ocupa espaço na mídia. E esses valores, dentro da sociedade moderna, são fundantes e decisivos nas relações entre as pessoas.

Naturalmente a recorrência ao termo "promocional" acarretou uma aproximação com as teorias de marketing, entendidas como um conjunto de ações que, estrategicamente formuladas, visam influenciar o público em relação a ideias, marcas, produtos ou serviços. No universo empresarial, o marketing é responsável pelas atividades de promoção e de distribuição de produtos, em consonância com a capacidade de produção de uma empresa e com a demanda atual ou potencial do mercado. Diz respeito, então, a um conjunto de procedimentos voltados para a criação e a oferta de mercadorias ou serviços, sem deixar de considerar seu caráter lucrativo: marketing é a análise, organização, planejamento e controle dos recursos da empresa, gerados a partir do consumidor com o objetivo de satisfazê-lo em suas necessidades e desejos, de forma lucrativa (Kotler, 2003: 137).

Nessa medida, o marketing sinaliza, de um lado, as iniciativas traçadas por uma 
empresa para definir estratégias de ação; e, de outro, as práticas concretas que envolvem o fluxo de produtos ou serviços entre produtor e consumidor. Nessa direção, oscila entre uma filosofia de orientação para o mercado e um conjunto de práticas do composto mercadológico. A aproximação com a noção de marketing é no âmbito de sua compreensão filosófica, pois tem a ver com a posição de uma empresa no mercado, com suas políticas de inserção e com a sua forma de atuação.

Nessa perspectiva, a ação promocional, presente na e pela televisão, centrada nas ações de propagação de informações, de qualificação de produtos e, principalmente, de conferência de valor e prestígio recorre aos mesmos planejamentos afeitos ao marketing. É regida, assim, pela lógica econômica, por estar ligada ao desenvolvimento e à permanência de uma empresa no mercado; tecnológica, por ser responsável pela conformação das imagens, qualidade e quantidade de difusão, formas e práticas de consumo; e simbólica, por organizar discursivamente as mensagens midiáticas, considerando as linguagens convocadas e as gramáticas que sobredeterminam sua expressão.

Esse percurso contempla, de certa forma, a proposta defendida por Péninou, em relação à publicidade, que já alertava para a necessidade de um espírito de sistema (Péninou, 1972), o que acarretaria uma reflexão primordial sobre suas lógicas de funcionamento e suas articulações mais profundas. Aliás, a necessidade de um olhar macro sobre o fenômeno, aliada à metodologia de vertente semiótica, é a base das projeções aqui defendidas.

A visão sistêmica implicou o direcionamento do estudo para a noção de gênero, entendido como uma instância abstrata, de feição classificatória que agrupa espécies que se relacionam e que se distinguem umas das outras por traços marcantes. $\mathrm{O}$ gênero constitui um domínio de conhecimento a partir do qual se atualizam diferentes subgêneros, que, por sua vez, se manifestam em formatos distintos e particularizantes. Dessa forma, do ponto de vista das relações entre o mundo e o discurso, o gênero constitui uma instância da ordem da arquitextualidade, que se atualiza em categorias, determinando os diferentes subgêneros, para só então manifestar-se em formatos 
particulares.

Em se tratando daquilo que aqui se propõe chamar de gênero promocional, o desafio é investigar seu princípio constitutivo, o tipo de relação que propõe, o tipo de mundo que projeta, sobre que elementos incide sua ação e suas possibilidades articulatórias. Esse conjunto de questões desencadeou um movimento de construção daquilo que se denominou chamar de gramática do promocional em televisão.

\section{Gramática do gênero promocional}

Normalmente quando se estuda o gênero televisivo na perspectiva discursiva, importa identificar o tipo de mundo que suas produções projetam e o regime de crenças que mobilizam junto aos telespectadores. As produções jornalísticas, por exemplo, operam sobre o mundo factual, aquele de veracidade constatável, e levam o telespectador a crer nessa realidade: quando a notícia é sobre um acontecimento como o naufrágio de um navio, o telespectador acredita nos fatos, sabe que eles realmente aconteceram e sobre eles projeta interpretações. As telenovelas pautam sua narrativa no mundo ficcional, em uma abordagem fantasiosa da realidade, levando o telespectador a um regime de crença da ordem da verossimilhança: por mais que as tramas apresentadas tenham proximidade com a realidade, o telespectador tem consciência de que elas não passam de situações imaginárias. Já as produções como os reality shows, do tipo Big Brother, criam uma realidade paralela à televisão, reprodução de uma situação artificial com regras próprias, e levam o telespectador a operar em cima dessa realidade construída.

Sendo assim, o telespectador, quando decide, por exemplo, assistir a um telejornal, ele em princípio já sabe o que o formato oferece, muitas vezes conhece os apresentadores, bem como está acostumado com o cenário e com o tom do programa, pautado no maior ou menor envolvimento com a notícia. Também em relação à telenovela, o telespectador parte de alguns conhecimentos já postos: núcleos temáticos, 
localização da trama, desdobramentos da narrativa, mas sempre sabendo, de antemão, tratar-se de ficção. Por mais que as notícias apresentadas ou os desdobramentos da trama ficcional sejam novos, alguns dados estão pressupostos no próprio formato e denotam familiaridade com os telespectadores. Esse entendimento de gênero (Duarte, 2004) constitui uma base bastante sólida aos estudos das produções televisivas.

Com a produção promocional, entretanto, as peculiaridades são de outra ordem: por mais que o telespectador reconheça o intervalo como o espaço dos anunciantes, ele desconhece os produtos que serão anunciados, sua duração e mesmo quantidade, e também aqueles que aparecerão no interior dos programas, sob a forma de merchandising. Nesse sentido, o efeito surpresa é muito mais recorrente, sobretudo se se levar em conta que o grande desafio das produções dos intervalos é sempre distanciar-se das formas comuns, impostas pelo uso, para inaugurar uma apresentação inédita. $\mathrm{O}$ desafio, na medida do possível, é sempre surpreender o telespectador para conseguir sua simpatia, sua adesão e, por fim, levá-lo às ações de compra.

Por isso o fator desencadeador da produção promocional não é apenas o tipo de mundo que é projetado, mas, sim, e com maior intensidade, o estímulo ao consumo, à ação de tornar algum produto ou serviço de utilidade para o sujeito consumidor, satisfazendo necessidades primárias ou secundárias. Como se vive em uma sociedade de consumo, ocupa prioridade a otimização de lucros por meio da oferta de mercadorias e serviços que, supostamente, sejam adequados às exigências e às preferências dos consumidores. Nessa dimensão, a base da promocionalidade é bastante peculiar: tem caráter mercadológico, pois responde aos interesses de uma empresa (televisão) que precisa ter bons resultados financeiros para continuar operando no mercado de comunicação. E, por isso, precisa recorrer a ações que chamem a atenção do telespectador para a causa proposta, que estimulem o processo de troca e que garantam a adesão ao que lhe é ofertado.

E como essa lógica está presente no eixo comunicativo, ela incide sobre os elementos que compõem esse processo: o produtor (enunciador), o objeto (produto, marca, serviço) ou o receptor (enunciatário). 
Quando a promoção recai sobre o produtor, o resultado são as ações que falam do enunciador ou daquilo que ele produz ou patrocina. Em televisão, incluem-se aqui chamadas a programas da própria grade, ações socioeducativas desenvolvidas pela emissora/empresa, campanhas institucionais da empresa, parceria em projetos sociais, reiteração da fala sobre si mesma. Cria-se, nesse caso, uma relação de reflexividade, na medida em que o foco da promoção volta-se para o próprio enunciador.

A promoção que recai sobre o produto constitui aquilo que comumente se vê nos anúncios publicitários: é o anunciante que divulga, pela mídia televisiva, seu produto, marca, serviço, para obter o maior número possível de simpatizantes. Como a televisão, no Brasil, tem um alcance significativo de público, os anunciantes recorrem a essa mídia para conquistar um número certamente maior de consumidores. O mesmo vale para os produtos anunciados no interior dos programas em forma de merchandising. Como, nesse caso, o foco é o produto, a relação instaurada é de transitividade.

Por fim, a promoção pode recair sobre o telespectador (enunciatário), por ser a mídia que assegura, a quem nela aparece, uma posição diferenciada e favorável na sociedade. Aparecer na televisão dá projeção, garante retorno, repercute no meio social, e, por isso, as pessoas tanto se empenham em nela aparecer, configurando aquilo que se denomina de relação de reciprocidade. Para quem deseja exposição, status e prestígio, é na telinha que se obtém esse reconhecimento.

Na sociedade atual, pode-se dizer que a promocionalidade decorre da condição de consumo que regula a realidade social, diferencia os consumidores, impulsiona o mercado e traz retornos financeiros às organizações. Dessa forma, divulgando ou conferindo prestígio, a promocionalidade instaura-se como um movimento que tem como princípio constitutivo a lógica mercadológica, a qual, por sua vez, incide sobre enunciador, produto ou enunciatário, com eles contraindo, respectivamente, como se referiu, relações de reflexividade, transitividade ou reciprocidade.

Em um segundo momento, na atualização desse gênero em subgênero, a ação promocional mobiliza categorias ou subcategorias que resultam em possibilidades discursivas de diferentes ordens. Com esse entendimento, o subgênero é reconhecido 
por sua natureza macrotemática e compreende tanto a posição assumida pelo enunciador e aquela projetada para o enunciatário, como as intencionalidades buscadas na comunicação. Tais estratégias dizem respeito, por exemplo, à forma de inserção na grade, resultando em subgêneros autônomos ou difusos: no primeiro caso, trata-se de produtos independentes, de configuração própria e com espaços específicos que não estão atrelados a programas, normalmente veiculados nos intervalos dos programas; no outro, trata-se de inserções (quadros, falas, remissões) de caráter promocional, feitas no interior dos programas.

Outra categoria diz respeito à condição do anunciante: externo (aquele que compra o espaço na televisão, considerada como veículo, para expor e divulgar seus produtos) ou interno (anunciante e empresa se fundem, criando um discurso voltado à projeção da própria empresa de comunicação).

O resultado são os subgêneros promocionais assim conhecidos:

- chamadas a programas ou programação: referência a programas ou à programação como um todo, com exibição de pequenos flashes de cenas gravadas ou, ainda, de remissões explícitas, para serem veiculados nos intervalos ou no interior da programação;

- ação socioeducativa: programetes de curta duração que trazem mensagens de cunho social, cultural ou educativo, com vistas a difundir causas e promover ensinamentos, com a chancela, ou por iniciativa, da emissora;

- campanha ou ação socioinstitucional: ações ou campanhas encabeçadas pela empresa que, de acordo com a política do grupo empresarial, auxiliam no reforço da imagem corporativa da empresa, no interior da comunidade em que atua;

- comercial ou peça publicitária: espaços de curta duração que, em forma de spots, divulgam produtos, marcas, serviços, normalmente de anunciantes externos que compram espaço na televisão, com vistas a atingir o maior contingente de público para as suas ofertas;

- vinheta de abertura: vinheta que caracteriza um determinado programa, sempre reiterada, no início e no fim da emissão, durante o período de exibição daquele 
programa;

- programas: programas de natureza eminentemente metadiscursiva, que têm, como tema, acontecimentos, fatos, bastidores, como preparação de personagens, gravação de cenas, ilhas de edição e de produção, como é o caso de Vídeo Show, da Rede Globo;

- identidade visual do anunciante externo ou da emissora: logomarca exibida com todos os recursos da tecnologia disponíveis, veiculada isoladamente entre os programas; junto a ações de interesse social, como cidadania, teatro, cultura, entre outros; ou sobreposta, no canto da tela;

- merchandising comercial, social e autorreferencial: inserções de produtos, marcas, serviços (comercial); alusões a temas, ideias, valores (social), ou remissões a produtos da própria emissora (autorreferencial), dentro de um programa em curso;

- quadros: inserção de atores, apresentadores, âncoras, editores em outros programas ou atividades da emissora; explicitação das conquistas obtidas, pela empresa, no campo da moderna tecnologia, sempre com a intenção explícita de valorizar o próprio fazer.

Essas possibilidades são configuradas em formatos que constituem as manifestações concretas a que se tem acesso. Entre esses formatos, pode-se destacar a ação socioeducativa Crack nem pensar, lançada por uma emissora regional, afiliada da Rede Globo, em 2008, e que se constituiu em bandeira social da empresa nos dois anos em que foi veiculada. É o caso, também, do merchandising da Renault, na telenovela $A$ vida da gente ${ }^{2}$, em que o personagem Renato é contratado por uma revenda da marca e recebe instruções do colega sobre como agir com o cliente na venda de carro. Além da fala dos personagens, o produto está presente no cenário (na logomarca em pano de fundo, no carro) e no jaleco vestido pelos funcionários.

O quadro, na sequência, sintetiza a proposição aqui desenvolvida para a gramática do gênero promocional televisivo:

2 Telenovela exibida pela Rede Globo de Televisão, em 2010/11, no horário das 18h. 
Estudos em Jornalismo e Mídia - Vol. $10 \mathrm{~N}^{\circ} 2$ - Julho a Dezembro de 2013

ISSNe 1984-6924

DOI: http://dx.doi.org/I0.5007/I984-6924.20I3v10n2p340 
Estudos em Jornalismo e Mídia - Vol. 10 NN$^{\circ} 2$ - Julho a Dezembro de 2013

Gramática do gênero promocional televisivo

\begin{tabular}{|c|c|c|c|c|c|c|}
\hline \multicolumn{4}{|c|}{$\begin{array}{c}\text { Gênero } \\
\text { (ordem da virtualidade) }\end{array}$} & \multirow{2}{*}{\multicolumn{2}{|c|}{$\begin{array}{c}\text { Subgênero } \\
\text { (ordem da atualização) }\end{array}$}} & \multirow[t]{2}{*}{$\begin{array}{c}\text { Formato } \\
\text { (ordem da realização) }\end{array}$} \\
\hline Lógica & incidência & relação & função & & & \\
\hline Mercadológica & $\begin{array}{l}\text {-produto } \\
\text {-enunciador } \\
\text {-enunciatário }\end{array}$ & $\begin{array}{l}\text {-transitividade } \\
\text {-reflexividade } \\
\text {-reciprocidade }\end{array}$ & $\begin{array}{l}\text {-publicizar } \\
\text {-conferir } \\
\text { prestígio }\end{array}$ & autônomo & $\begin{array}{l}\text {-chamada (prog. ou } \\
\text { programação) } \\
\text {-ação socioeducativa } \\
\text {-campanha ou ação } \\
\text { socioinstitucional } \\
\text {-comercial ou peça } \\
\text {-vinheta de abertura } \\
\text {-programa } \\
\text {-identidade visual (logomarca } \\
\text { de anunciante externo ou da } \\
\text { emissora) }\end{array}$ & $\begin{array}{l}\text { Samba da globalização } \\
\text { Um novo tempo } \\
\text { Crack nem pensar } \\
\text { Universitário } \\
\text { vinheta Fantástico } \\
\text { vinheta Rede Globo }\end{array}$ \\
\hline & & & & difuso & $\begin{array}{l}\text {-chamada (referência a outros } \\
\text { programas) } \\
\text {-identidade visual (logomarca } \\
\text { de anunciante externo ou da } \\
\text { empresa) } \\
\text {-merchandising comercial } \\
\text {-merchandising social } \\
\text {-merchandising } \\
\text { autorreferencial } \\
\text {-quadros }\end{array}$ & $\begin{array}{l}\text { Bonner chama um outro } \\
\text { programa } \\
\text { Renault na novela } \\
\text { "Impotência" na novela } \\
\text { Belissima para Belissima } \\
\text { inserção de atores no } \\
\text { Faustão }\end{array}$ \\
\hline
\end{tabular}

\section{Análise das peças}

Para o estudo do formato promocional, selecionaram-se cinco chamadas da Rede Globo de Televisão ${ }^{3}$, produzidas e veiculadas nos últimos anos: duas de final de ano (2009 e 2011) e três do carnaval (2008, 2010 e 2012), cada uma com duração de cerca de um minuto, para serem analisadas quanto à construção temática, trilha musical, estrutura narrativa e principais estratégias discursivas, concernentes ao tratamento de tempo e espaço, de configuração sugerida, de papel dos atores, de tonalização.

A chamada de final de ano, na Rede Globo, embalada pelo jingle Um novo tempo, constitui quase uma tradição na emissora, na medida em que vem sendo veiculada, sempre no mês de dezembro, há mais de trinta anos. A escolha por essas duas (2009 e 2011) é justificada em função das diferentes estratégias utilizadas na produção discursiva, em cada uma das peças.

Embora a chamada do carnaval Samba da Globalização venha sendo exibida desde 2008, e sempre com soluções inovadoras a partir da música criada, as três 3 Todas as peças foram cedidas pela Rede Globo para análise neste trabalho. 
selecionadas para análise já demonstram o relativo sucesso do formato, com as estratégias discursivas privilegiadas.

\section{Chamada 1: Um novo tempo}

- Construção temática ligada a acontecimento do mundo real

Uma visível preocupação, reconhecida nas chamadas, é sua ambientação, pois ela mostra relação estreita com momentos do mundo real, para aproveitar o clima proporcionado pelo período e buscar a pretendida identificação entre o acontecimento e a emissora.

Os festejos natalinos e as expectativas de um ano novo, período de forte apelo emocional, vêm sempre acompanhados pelo balanço das realizações, pelo espírito de confraternização e, naturalmente, pela projeção de planos futuros. Sendo assim, esse momento efervescente torna-se cenário perfeito para a emissora, sistematicamente, levar sua mensagem ao público e mostrar sua disposição de compartilhar essas emoções com todos. A exploração dessa realidade nas produções televisivas tem mais chance de encontrar eco junto ao telespectador, e garantir aceitação por parte do público.

As peças de final de ano são um caso exemplar dessa tendência. Preparadas com esmero e envolvendo todos os recursos de produção, elas normalmente servem de palco para exibição do elenco, enaltecimento das qualidades da emissora, valorização das parcerias, alcance das conquistas tecnológicas, consolidação de poder da empresa.

- Criação de trilha sonora exclusiva

As peças de final de ano estruturam-se em torno de uma composição musical feita exclusivamente para o momento, como é o caso da música Um novo tempo ${ }^{4}$, composta pelo jornalista e compositor Nelson Motta e os irmãos Marcos e Paulo Sérgio Valle, a pedido de um ex-diretor da Globo, José Bonifácio de Oliveira Sobrinho (Boni).

4 Um novo tempo: Hoje é um novo dia, / de um novo tempo que começou. / Nesses novos dias, / as alegrias serão de todos, é só querer. / Todos nossos sonhos serão verdade, / o futuro já começou. / Hoje a festa é sua, / hoje a festa é nossa, / é de quem quiser, quem vier. / Hoje a festa é sua, / hoje a festa é nossa, / é de quem quiser, quem vier. 
A música inaugurou, na época de sua criação, uma nova forma de a emissora interagir com seu telespectador, e, a partir daí, passou a ser retomada anualmente, em novos cenários, sempre para celebrar a data festiva. Misturando mensagem otimista com emoção das festas natalinas, além da mobilização de todo o elenco da emissora, a composição tem-se revelado, nesses anos, uma estratégia positiva de identificação com o público, sem esquecer, naturalmente, a valorização da emissora.

Em 2009, ano da comemoração dos 45 anos da Globo, a composição ganhou alguns acréscimos na sua letra e foi apresentada, segundo Adilson Xavier, diretor de criação da agência, em ritmo de hip-hop. Com essas alterações, privilegiou e exaltou a diversidade: assim convocou apenas alguns atores, o que representou uma inovação, mas deu grande destaque aos parceiros, aos projetos sociais e, sobretudo, ao telespectador. Em 2011, a música original foi retomada integralmente, ficando a inovação por conta da participação de um cantor de expressão nacional, Roberto Carlos, que conduziu a música e comandou o elenco em coro.

- Estrutura narrativa e estratégias

A chamada de $2009^{5}$, embora se valendo da música original, fez alguns acréscimos à letra, para dar conta do tema da campanha Vamos abraçar as diferenças, que privilegiava a diversidade. E a música, um pouco estendida e cantada por todos, constitui o fio condutor da narrativa, que se estrutura, assim, em uma junção produtiva de trilha musical e sequência de imagens.

As imagens, por sua vez, contemplam os diferentes segmentos que interagem com a emissora: o telespectador comum, respeitada sua diferença social, racial, cultural; os grupos que contam com o apoio da emissora (Voz do Morro, Afroreggae, Criança Esperança); o elenco de poucos programas (A Grande Família, Casseta \& Planeta, Jornal Nacional, Esporte Espetacular) e alguns atores.

A narrativa, construída na sucessão de imagens rápidas, atemporais, sem cenário aparente, recebe todo um tratamento estético, envolvendo direção de arte,

5 A versão de 2009 foi uma criação da agência Giovanni+Draftfcb e, na produção, foi dirigida por Ronaldo Soares. Ao todo, foram 36 horas de gravação, com participação de 108 atores e equipe técnica de 110 pessoas. 
enquadramento de planos, plasticidade de movimentos, e até interferência de animação para imprimir qualidade e efeito de magia ao produto final.

Os atores da narrativa - telespectador anônimo, grupos de parceiros, artistas, apresentadores - reforçam a configuração da heterogeneidade e da riqueza cultural dos públicos que interagem com a emissora, e que aqui aparecem, todos juntos, para, nas palavras de Adilson Xavier, celebrar a diversidade brasileira na mensagem de final de ano que desemboca nos 45 anos da Globo.

Dessa forma, juntando música e imagens, o resultado é uma composição com significativa qualidade estética, em que predominam os traços de encantamento, de magia, de sedução, e tudo é complementado pelo fechamento que traz a logomarca da emissora, e os dizeres: Globo 45 anos. Em 2010, a gente se vê por aí.

A peça de $2011^{6}$, embalada pelo tema $A$ gente se liga em você, traz uma outra proposta narrativa: tendo como fio condutor a música cantada por Roberto Carlos, do início ao fim da peça, as imagens simulam uma reunião familiar em que as pessoas se preparam para a festa de confraternização, envolvendo espera das crianças, chegada de algum parente, recebimento de correspondência, decoração da casa, movimentação da família, preparação do cardápio, cuidado com o bebê. No desenrolar da narrativa, alguns monitores, postados no cenário, mostram o cantor em ação, até os momentos finais, quando a tela se abre e ele aparece acompanhado do elenco da emissora, formando um coral.

No breve tempo de duração da história, montada em um ambiente cenográfico, com praça e casa intensamente iluminadas $(7200 \mathrm{~m}$ de lâmpadas lineares e $3000 \mathrm{~m}$ de outros tipos de luzes), a ideia, segundo Jayme Monjardim, é proporcionar um encontro da família brasileira com as estrelas da Globo, as quais se investem de funções muito típicas do cotidiano de todos: é o motorista de táxi (Luciano Huck) que traz a pessoa esperada; o sorveteiro (Serginho Groisman) que distribui sorvete às crianças na praça; os funcionários que decoram a casa (Renato Aragão e Dedé Santana); a empregada (Ana

6 A versão de 2011 é uma criação da Central Globo de Comunicação em parceria com a agência W/McCann, com direção de Jayme Monjardim e João Daniel Tikhomiroff. Foram mais de 10 dias de préprodução, envolvendo cerca de 500 profissionais. 
Maria Braga) que prepara o menu; o carteiro (William Bonner) que entrega encomendas; a babá (Xuxa Meneghel) que atende a criança; a arrumadeira (Angélica) que auxilia na decoração da árvore de natal; o garçom (Fausto Silva) que serve os convidados. O resultado é um trabalho visual que alia o esmero da cenografia e a potência da iluminação com a produção de arte.

O impacto na composição dos atores fica por conta da inversão de papeis em que pessoas comuns assumem o lugar de protagonistas na festa e os artistas tornam-se "pessoas comuns", configurando, na narrativa, a simulação de uma relação de intimidade e de parceria entre a emissora e o telespectador.

Ao explorar o entrosamento entre música, luz e imagem, a peça cria um efeito de sentido que vai da delicadeza da mensagem à exuberância da produção, coroada pela imagem final que traz a logomarca da emissora e os dizeres: 2012. A gente se liga em você.

\section{Chamada 2: Samba da Globalização}

- Construção temática ligada a acontecimento do mundo real

A preocupação de fusão com o acontecimento também vale para o carnaval, típica manifestação do povo brasileiro, e uma das festas populares mais animadas e representativas do mundo. Originário do entrudo português, onde, no passado, as pessoas jogavam, umas nas outras, água, ovos e farinha, até hoje se mantém como o período ligado à liberdade, sintetizando a celebração da alegria, da liberação, da descontração. Durante os dias de carnaval, o país fica praticamente à mercê dos festejos, e também aqui a mídia concentra sua pauta, ressaltando preparativos das escolas de samba, festas de rua, primeiros blocos, ensaios, personalidades ligadas ao evento etc.

A mesma estratégia parece ter sido o mote para as peças do carnaval. Semelhante à prévia que as escolas fazem na televisão, quando gravam trechos de seu samba enredo e mostram cenas alusivas ao desfile (embora feitas em estúdio), a chamada da Globo tem a mesma estrutura, chegando a confundir o telespectador pela simulação de uma nova escola. O texto do samba enredo faz desfilar os programas, 
Estudos em Jornalismo e Mídia - Vol. $10 \mathrm{~N}^{\circ} 2$ - Julho a Dezembro de 2013

reforçados pela inscrição da letra da música, sobreposta no vídeo, e pela exibição das respectivas logomarcas, pontuando os segmentos oferecidos (jornais, filmes, novelas, talk shows, programas infantis e de esporte), os apresentadores mais conhecidos, os programas em continuação e aqueles a serem lançados no ano, as ações de empresa etc. Nada mais contundente para atingir o imaginário do público!

- Criação de trilha sonora exclusiva

Samba da Globalização $o^{7}$ é uma criação divertida de Arlindo Cruz que, em parceria com Hélio de La Peña (do Casseta \& Planeta), Mu Chebabi e Franco Lattari, combinam as atrações da emissora com o fenômeno da globalização na composição do tema desse samba inédito. A experiência, aliando inovação e impacto, foi tão bem sucedida que o samba tem sido reiterado nos últimos cinco anos, com pequenas modificações na letra (decorrente das novas atrações no ano), mas grandes alterações na forma de apresentação.

Em todas as chamadas, a música criada, Samba da Globalização, é conduzida por Arlindo Cruz e sua banda que transformam esse samba enredo em uma forma de exaltação: é a celebração dos programas na e pela televisão que, além disso, apresentase e explicita-se como "uma grande família", como "um time campeão".

- Estrutura narrativa e estratégias

A peça inaugural, de $2008^{8}$, concentra, em uma única narrativa, a estrutura de samba enredo própria do carnaval: sequencialidade, estrutura clipada, sobreposição de

7 Segue, aqui, a letra do primeiro samba enredo (2008) que praticamente se mantém até hoje. As pequenas modificações nas letras, ocorridas nos anos seguintes, foram em função das alterações na grade de programação do ano.

Samba da Globalização: Uma Grande Família assim vira Zorra Total / quando rola um auê, / Sai até no Jornal Nacional / Vale a Pena de novo se ver na TV / É Casseta de outro Planeta / Dá pra ver Estrelas, toma Lá, Dá Cá / É Fantástico ter o Faustão, o Jô e o Didi / juntos num Caldeirão. / Com alegria até Altas Horas eu pude notar / Me liguei que o Globo Esporte é Espetacular / Tomei Ciência da Ecologia, da Periferia, / Da terra e da gente, / O filme depois da Novela deixa a Tela Quente / Mas quem te viu, quem te vê Globinho / Como você cresceu! / Assisti outro dia no Vídeo o Show que você deu / Globo Repórter é BBBeleza, / E pra ser Mais Você, é muita Malhação / Mais uma vez, é o time da Globo que é campeão / É na palma da mão, / Não é mole não, meu irmão, não é mole não, / A vida imitando a arte, isso é globalização / Não é mole não, meu irmão, não é mole não, / A vida imitando a arte, isso é globalização, plim plim.

8 A chamada foi produzida pela Divisão de Propaganda da Central Globo de Comunicação. 
imagens, tomada dos músicos, ritmo forte e agitada movimentação. O fio condutor é, assim, a música, comandando as imagens sobrepostas, que trazem o toque dos músicos e a referência aos programas representados por suas logomarcas. Para criar esse efeito de peça carnavalesca, a produção foi dividida em duas partes: uma no estúdio, com Arlindo e os músicos; outra em um botequim, no bairro de Santa Teresa, no Rio de Janeiro, onde 21 monitores foram posicionados em frente a mesas do bar. Já na fase de pós-produção, as imagens dos cantores foram inseridas nos monitores.

Dessa forma, na representação dos atores, o papel principal cabe ao monitor da tevê que acolhe os músicos e as logomarcas dos programas, configurando essa ideia de roda de samba, mas dentro da televisão.

Semelhante às tradicionais peças de carnaval, o tom é envolvente e o ritmo contamina qualquer telespectador. $\mathrm{O}$ fechamento da peça é a logomarca da emissora em tela cheia complementada pela referência "plim, plim", espécie de marca registrada da Globo, como mais um reforço à emissora e a suas produções.

A versão de $2010^{9}$ vale-se de outra estratégia: ainda que o samba enredo continue brincando com os programas da emissora, há dois temas do mundo real acrescentados ao samba: a Copa do Mundo e as Eleições 2010. Em função disso, mantém-se o fio condutor que é o samba, comandado por Arlindo Cruz e sua banda, mas o cenário assume outra projeção: tudo se passa no estádio de futebol mais importante do país, o Maracanã. Dessa vez, os monitores são dispostos no centro do campo, assim como no lugar das arquibancadas do estádio (as pessoas aparecem dentro das telas de tevê), assinalando, mais uma vez, o papel único que o monitor ocupa na chamada. O início, como uma partida de futebol, mostra o acendimento dos holofotes, os cliques das máquinas fotográficas, a busca pelos "ídolos", que são os monitores. Como na versão anterior, neles se alternam imagens dos músicos e das logomarcas dos programas referidos na samba enredo. Esse imbricamento é obtido pela combinação de dois momentos: cenas dos músicos e da torcida, captadas em estúdio, e, depois,

9 A versão de 2010 é uma criação de Felipe Plauska e Fernando Conde, com direção de Sérgio Glasberg. 
incorporação dessas imagens ao cenário. A chamada combina, com competência e criatividade, imagens reais e computação gráfica, fazendo uso de muita tecnologia 3D.

Também aqui o tom é contagiante, reforçado pelo fechamento da peça que celebra as comemorações, com uma tomada geral do estádio, complementada pela iluminação dos fogos. Sobre essa imagem, aparece a logomarca da emissora que depois se sobrepõe em tela cheia, acompanhada do refrão "plim-plim", tão característico da Rede Globo.

A versão de $2012^{10}$ traz novamente o cantor Arlindo Cruz entoando a letra que faz graça com os nomes das atrações da casa. A estratégia, agora, não é mais a gravação isolada para a incorporação posterior aos monitores. Trata-se, isto sim, de levar o carnavalesco aos estúdios dos programas (foram doze ao todo: A Grande Família, Jornal Nacional, Bom Dia Brasil, Fantástico, Caldeirão do Huck, Altas Horas, Jornal Hoje, Amor e Sexo, TV Globinho, Vídeo Show, Mais Você e Esporte 2012), para interagir diretamente com seus atores, apresentadores, jornalistas, incluindo até, em alguns, a presença do auditório. Estes, por sua vez, junto com o sambista, mostram-se mais descontraídos, movimentam-se em cena, sambando, gingando, batucando, para receber o convidado ilustre. Os demais programas referidos no samba continuam representados pelas logomarcas, em telas espalhadas por esses cenários.

Semelhante às tradicionais peças de carnaval, a chamada empresta mais empolgação àqueles cenários formais, principalmente os estúdios dos telejornais, imprimindo um tom animado, descontraído e lúdico.

Nos momentos finais, a peça reforça o clima carnavalesco com a presença da passista Aline Prado, a mulata Globeleza, símbolo global do carnaval da emissora, a valorização do cenário exuberante, com a logomarca ao fundo, e a batida forte dos instrumentos musicais. No fechamento, novamente o "plim-plim", a logomarca em tela cheia e os dizeres $A$ gente se liga em você.

10 A versão de 2012 teve a direção de Oscar Rodrigues Alves. 


\section{Considerações finais}

Conforme se buscou demonstrar, muito além de educar, informar ou entreter, a emissora de televisão está submetida às exigências econômicas, o que envolve posição no mercado, disputa por índices de audiência e, assim, garantia de viabilidade de seu negócio.

Semelhante ao marketing, a promocionalidade identifica-se com esse composto de ações que respondem aos apelos mercadológicos e à rentabilidade econômica da uma empresa, aproximando-se, por vezes, do fazer publicitário, mas indo além, na medida em que instala suas próprias regras para esse fazer.

Essa condição faz da promocionalidade um fenômeno que, verdadeiramente, perpassa o fazer televisivo e impregna todas suas ações. É uma ação genérica, ampla, que concentra tanto o movimento de divulgar, de tornar públicos produtos, imagens, marcas, serviços, com vistas a influenciar o comportamento das pessoas; como o movimento de projetar, de exaltar, de conferir prestígio a tudo que é veiculado na telinha.

No plano discursivo, a promocionalidade se institui como um gênero, cujo princípio fundador é a ordem mercadológica, que sobredetermina todas as produções feitas no âmbito da televisão. Nessa condição, além de destacar o produto, seu alvo maior, tem a peculiaridade de contemplar os dois polos do eixo comunicativo: agradar o telespectador (enunciatário) e, ainda, valorizar a empresa (enunciador).

Dentro desse contexto, a formulação de uma gramática do promocional responde ao desafio de examinar as regras desse promocional, implicando um reconhecimento de suas instâncias articulatórias: a virtualidade de seu princípio constitutivo, a atualização em categorias ou conjunto de categorias e sua concretização em formatos variados e diferenciados.

Um exemplo marcante de formato promocional é a chamada autorreferencial, pelo investimento pesado que as emissoras destinam a esse tipo de produção, pelas soluções inovadoras e surpreendentes que alcançam e pela invocação que conseguem 
fazer da própria produção, emissora, empresa.

A Rede Globo de Televisão em especial, nesses últimos cinco anos, alcançou patamares bastante diferenciados em relação a essa fala de si mesma, pois, como o vem fazendo, propôs formatos criativos e bastante incomuns.

As mensagens de final de ano (2009 e 2011) e as chamadas de carnaval (2008, 2010 e 2012) são exemplos disso. Associando fala autorreferencial com acontecimento real, as chamadas procuram inserir-se no cotidiano do telespectador, traduzindo e expressando sentimentos que são próprios da ocasião: emocionalidade natalina e diversão carnavalesca. E, junto, a empresa empresta qualidade ao formato, exalta seus fazeres e estreita sua relação com o telespectador.

Além disso, a mensagem de final de ano, retomando a canção especialmente construída há mais de 30 anos, assinala a busca do novo sem abdicar do mesmo, a tensão entre a repetição e a inovação, o que corresponde ao jogo entre previsibilidade e imprevisibilidade, entre o que dela se espera e o efeito surpresa. A chamada situa-se assim no limiar entre aquilo que é inédito, diferente, novo, e aquilo que dela se espera, o procedimento previsível, e tudo isso é feito de forma a aliar a simplicidade de propósito com a sutileza do dizer. Por isso a mensagem de final de ano está sempre recebendo novas configurações. Os dois exemplos apresentados corroboram essa tendência: é a mesma melodia, o mesmo período de veiculação, mas com propostas completamente diferenciadas e atraentes, em um jogo impactante de imagem e música, para, no fundo, exaltar a empresa de comunicação.

A chamada de carnaval surpreende, em primeiro lugar, pelo ineditismo, nascido, em 2008, de uma brincadeira com os nomes dos programas que redundou na criação desse samba enredo que fala da programação da emissora. O diálogo que se instala entre esses dois mundos, aproximando a ludicidade da festa carnavalesca com a riqueza das atrações da emissora, é inesperado e envolvente. O resultado é um formato menos rígido que elimina de imediato a solenidade e o peso do discurso verbal, para promover a ordem frívola dos signos, valorizando menos a excelência do produto e mais a dimensão estética. E o resultado mais efetivo da criação foram as reiteradas versões que se 
sucederam nos últimos cinco anos. Por mais familiaridade que agora exista com o samba enredo, os formatos obtidos continuam surpreendendo e causando admiração. Nada mais sugestivo e manipulatório.

A reflexão em torno do promocional televisivo, com a repercussão que desencadeia sobre as produções internas, as parcerias, os projetos sociais, mostra o quanto o fenômeno está intimamente relacionado com as políticas de ação de uma emissora de televisão, com a expansão de sua imagem e com a consolidação de sua marca. E o telespectador precisa ter consciência dessas articulações para perceber o que pode estar por trás de algumas produções a que assiste. 


\section{Referências Bibliográficas}

CASTRO, Maria Lília Dias de (2010): "Promocional: um percurso convergente entre mundos, mídias e plataformas", em DUARTE, Elizabeth Bastos e CASTRO, Maria Lília Dias de (orgs.). Convergências midiáticas: produção ficcional - RBS TV. Porto Alegre, Sulina. pp.35-44.

CASTRO, Maria Lília Dias de (2008): "Práticas publicitárias: o embaralhamento do discurso promocional", em DUARTE, Elizabeth Bastos e CASTRO, Maria Lília Dias de (orgs.). Em torno das mídias: práticas e ambiências. Porto Alegre, Sulina. pp.41-53.

CHARAUDEAU, Patrick (2006): Discurso das mídias. Tradução de Ângela M.S. Corrêa. São Paulo, Contexto.

DELGADO, Juan Benavides (1997): Lenguaje publicitário. Madrid, Síntesis.

DUARTE, Elizabeth Bastos (2004): Televisão: ensaios metodológicos. Porto Alegre, Sulina. Col. Estudos sobre o audiovisual.

FABBRI, Paolo (1999): El giro semiótico. Barcelona, Gedisa.

FLOCH, Jean-Marie (2003): Sémiotique, marketing et communication. 4.ed. Paris, PUF.

FONTANILLE, Jacques (2007): Semiótica do discurso. Tradução de Jean Cristtus Portela. São Paulo, Contexto.

JOST, François (2010): Compreender a televisão. Tradução de Elizabeth Bastos Duarte e Maria Lília Dias de Castro. Porto Alegre, Sulina.

KOTLER, Philip (2003): Marketing de A a Z. 4.ed. Rio de Janeiro, Elsevier.

LUHMANN, Niklas (2005): A realidade dos meios de comunicação. Tradução de Ciro Marcondes Filho. São Paulo, Paulus.

MARTÍN-BARBERO, Jesus (1997): Dos meios às mediações: comunicação, cultura e hegemonia. Rio de Janeiro, UFRJ.

PENINOU, Georges (1972): Intelligence de la publicité: étude sémiotique. Paris, Robert Laffont. SEMPRINI, Andrea (2006): A marca pós-moderna: poder e fragilidade da marca na sociedade contemporânea. São Paulo, Estação das Letras.

VERÓN, Eliseo (2004): Fragmentos de um tecido. São Leopoldo, Unisinos.

Página da Rede Globo de Televisão. Disponível em: http://redeglobo.globo.com/.

Este artigo e todo o conteúdo da Estudos em Jornalismo e Mídia estão disponíveis em http://www.periodicos.ufsc.br/index.php/jornalismo/index

Estudos em Jornalismo e Mídia está sob a Licença Creative Commons 